\title{
French Support for Caribbean Medical Cooperation
}

The Editor,

Sir,

Medical cooperation plays a major role in the improvement of healthcare in developing countries, including in the Caribbean region. Collective action to promote the health of the Caribbean people was taken several decades ago through the formation of the Caribbean Cooperation in Health (1). There have been improvements in important health indicators such as maternal and child health, and immunization. Partnerships and collaborations with international public health organizations facilitate linkages to global agendas for health. The $\mathrm{CCH}$ health agenda included human resources development and strengthening of health systems. However, access to health care and standard of care are still not uniform among the countries of the region (2).Little countries with fragile economies are particularly vulnerable when hit by recurrent tropical storms, as shown by the recent devastation occurring in Dominica (3).

The University Hospital of Fort-de-France initiated regional collaboration to assist Caribbean peoples to achieve the highest attainable level of health and sustainable development (4). This teaching hospital located in Martinique, one of the French Caribbean islands, has always been the primary point of referral for patients from other countries in the region, including sick tourists vacationing in the Caribbean. The aim of the process was to improve science education, to train health-care professionals and to strengthen research facilities, with the acknowledgment and understanding of the historical roles of the cultural, economic, and political aspects unique to the Caribbean. Direct training, long-distance 
learning, and internships in Fort de France are being offered to medical students and nurses. Therapeutic strategies can be discussed by videoconference, as well as advice for emergency and poisonings, allowing treatment of patients in their country of origin. Some nongovernmental institutions are accustomed to participating in such capacity-building programs (eg, The Caribbean Doctors Association).

European governments, particularly the French, should contribute to solidify plans for greater collaboration and cooperation with health agencies and hospital administrators of the region. For example, the medical cooperation should be able to establish and define the status of patients from neighboring islands hospitalized in French overseas departments accounting for approximately $15 \%$ of overall admissions. The inter-regional medical cooperation between the French departments of the Americas and the Caribbean countries is essential for the implementation and improvement of healthcare. With Europe's support, common solid relationships in training, collective scientific research and continuous medical education among the Caribbean professionals are the key success to revitalize health systems in the region.

Keywords: Caribbean, medical education, medical cooperation

D Resiere ${ }^{1,2}, R$ Valentino $^{1}$, Guerrier $^{2,3}$, B Mégarbane $^{2,4}$, M Didier $^{2}$, K Compton $^{2}$, F Roques ${ }^{1}$, H Mehdaoui ${ }^{1,2}$

From: ${ }^{1}$ Department of Critical Care unit, University Hospital of Martinique, Fort-deFrance, Martinique, France, ${ }^{2}$ The Caribbean Doctors Association, ${ }^{3}$ Cochin Hospital, ParisDescartes University, Paris, France, ${ }^{4}$ Department of Medical and Toxicological Critical Care, Lariboisière Hospital, Paris-Diderot University, INSERM U1144, Paris France

Correspondence: Dr D Resiere, Critical Care Unit, University Hospital of Martinique CS 90632-97261 Fort-de-France Cedex.Email : dabor.resiere@chu-fortdefrance.fr 


\section{REFERENCES}

1. Caribbean Cooperation in Health Secretariat. Caribbean Cooperation in Health Phase II: a new vision for Caribbean health. Bridgetown, Barbados. Available from: http://wwwcaricom.org/jsp/community/regional_issues/health initiative.jsp. Caribbean Community; 1999.

2. The United Nations Development Program: Latin America and the Caribbean. Available at http://www.latinamerica.undp.org.

3. BBC News. Latin America and Caribbean. Tropical Storm Erika hit Dominica, in the eastern Caribbean. Available at http://www.bbc.com/news/world-latin-america34091475.

4. Resiere $\mathrm{D}$, Valentino $\mathrm{R}$, Lucron $\mathrm{H}$, et al. Inter-regional medical cooperation in the Caribbean: lessons from the ongoing cooperation between Martinique, St Lucia, and Dominica. West Indian Med J 2014 (open); 1: 26. 